\title{
Sex and Gender Differences in Gastroesophageal Reflux Disease
}

\author{
Young Sun Kim, ${ }^{1}$ Nayoung Kim, ${ }^{2,3 *}$ and Gwang Ha Kim ${ }^{4}$ \\ ${ }^{\prime}$ Department of Internal Medicine, Healthcare Research Institute, Seoul National University Hospital Healthcare System Gangnam Center, Seoul, \\ Korea; ${ }^{2}$ Seoul National University Bundang Hospital, Seongnam, Gyeonggi-do, Korea; ${ }^{3}$ Department of Internal Medicine and Liver Research \\ Institute, Seoul National University College of Medicine, Seoul, Korea; and ${ }^{4}$ Department of Internal Medicine, Pusan National University School \\ of Medicine, Busan, Korea
}

It is important to understand sex and gender-related differences in gastroesophageal reflux disease (GERD) because gender-related biologic factors might lead to better prevention and therapy. Non-erosive reflux disease (NERD) affects more women than men. GERD symptoms are more frequent in patients with NERD than in those with reflux esophagitis. However, men suffer pathologic diseases such as reflux esophagitis, Barrett's esophagus (BE), and esophageal adenocarcinoma (EAC) more frequently than women. The prevalence of reflux esophagitis is significantly increased with age in women, especially after their 50 s. The mean age of EAC incidence in women is higher than in men, suggesting a role of estrogen in delaying the onset of BE and EAC. In a chronic rat reflux esophagitis model, nitric oxide was found to be an aggravating factor of esophageal injury in a male-predominant way. In addition, the expression of esophageal occludin, a tight junction protein that plays an important role in the esophageal defense mechanism, was up-regulated in women. This explains the male predominance of reflux esophagitis and delayed incidence of BE or EAC in women. Moreover, the symptoms such as heartburn, regurgitation, and extra-esophageal symptoms have been more frequently reported by women than by men, suggesting that sex and gender play a role in symptom perception. Differential sensitivity with augmented symptoms in women might have diagnostic and therapeutic influence. Furthermore, recent studies have suggested that hormone replacement therapy has a protective effect against esophageal cancer. However, an anti-inflammatory role of estrogen remains compelling, which means further study is necessary in this area.

(J Neurogastroenterol Motil 2016;22:575-588)

\section{Key Words}

Adenocarcinoma; Barrett esophagus; Esophagitis; Estrogen; Gender

\section{Introduction}

Gastroesophageal reflux disease (GERD) includes an entire spectrum of reflux diseases of the gastroesophageal junction. GERD complications include reflux esophagitis and Barrett's esophagus (BE). ${ }^{1}$ GERD is categorized according to endoscopy as reflux esophagitis and non-erosive reflux disease (NERD) ${ }^{2}$ Functional heartburn is defined as retrosternal burning discomfort or pain refractory to optimal anti-secretory therapy in the absence of gastroesophageal reflux, histopathologic mucosal abnormalities, major motor disorders, or structural abnormalities. ${ }^{3}$ Both functional

Received: August 24, 2016 Revised: September 12, 2016 Accepted: September 13, 2016

() This is an Open Access article distributed under the terms of the Creative Commons Attribution Non-Commercial License (http://creativecommons. org/licenses/by-nc/4.0) which permits unrestricted non-commercial use, distribution, and reproduction in any medium, provided the original work is properly cited.

${ }^{*}$ Correspondence: Nayoung Kim, MD, PhD

Department of Internal Medicine, Seoul National University Bundang Hospital, 82, Gumi-ro 173 beon-gil, Bundang-gu, Seongnam, Gyeonggi-do 13620, Korea

Tel: +82-31-787-7008, Fax: +82-31-787-4051, E-mail: nayoungkim49@empas.com 
heartburn and NERD are more common in women than in men. Currently, NERD is differentiated from reflux esophagitis by upper endoscopy because NERD does not show visible esophageal mucosal injury. NERD is further differentiated from functional heartburn by using 24-hour esophageal $\mathrm{pH}$ monitoring ( \pm impedance) with symptom-reflux correlation analysis. ${ }^{4,5}$ However, 24-hour esophageal $\mathrm{pH}$ monitoring has been criticized for having limited sensitivity in diagnosing GERD. ${ }^{4}$ In addition, it is an uncomfortable testing tool not commonly used in general practice. ${ }^{4}$ Accordingly, accurate discrimination of functional heartburn from NERD in the general population is limited. Most available data on NERD have been collected in epidemiological studies conducted on patients with heartburn using validated questionnaires and esophagogastroduodenoscopy without using pathophysiological evaluation such as 24-hour esophageal $\mathrm{pH}$ monitoring. ${ }^{6}$

It is commonly known that esophageal adenocarcinoma (EAC) arises from a sequential spectrum of GERD from reflux esophagitis, leading to $\mathrm{BE}$, and finally resulting in EAC. Interestingly, there is a male-predominant sex difference through the spectrum of reflux esophagitis, $\mathrm{BE}$, and $\mathrm{EAC} .^{7-9}$ In addition, the male to female ratios become higher with more progression towards EAC. ${ }^{7}$ Meanwhile, reflux symptoms and NERD generally affect more women than men. ${ }^{7,9}$ Epidemiological data have suggested that the esophageal mucosal epithelium is more fragile to refluxed gastroduodenal contents in men compared to that of women, ${ }^{7,10}$ although women are more susceptible to GERD symptoms than men.

Sex means a human's biological status based on their reproductive systems and functions assigned by chromosomal type. Gender means manners, feelings, and behaviors in a given culture associated with a person's sex stereotypes. ${ }^{11,12}$ Sex-specific medicine is a medical practice in which sex differences between female and male are recognized and actively utilized in medical study, diagnosis, treatment, and education. Sex-specific medicine assumes that sex is a crucial factor in the pathogenesis, risk factor, disease progression, and prognosis of many diseases. According to sex-specific medicine, treatment of certain diseases should be specified based on a patient's sex because female and male have different drug responses, prognoses, and risk factors. ${ }^{13,14}$ Thus, understanding sex and genderassociated differences in GERD is important for interpreting biological factors. They might provide better prevention and treatment protocols for both women and men.

However, there have been limited studies that investigate sexgender differences between women and men in the area of GERD in published articles. Recently, Asanuma et al. ${ }^{15}$ have nicely reviewed the sex difference of GERD incidence and the important role of female estrogen. However, they did not include sex and gender differences in the aspect of clinical manifestations, pathophysiology such as the brain-gut axis, or treatment. Therefore, the aim of this review was to focus on sex and gender differences with regard to prevalence, pathophysiology, clinical presentations, and treatment of GERD using available literatures.

\section{Methodology}

First, we searched the PubMed using MeSH terms combined with free text terms to have a broad coverage of articles on GERD using the following terms: sex, gender, epidemiology, pathophysiology, estrogen, symptoms, healthcare seeking, and treatment. Searches were then limited to full articles in English language.

All searches were completed by February 20, 2016. All retrieved abstracts were independently reviewed. Inclusion criteria were: (1) results that included gender differences and (2) original data were presented. Abstracts that met the inclusion criteria were reviewed to evaluate study design, clinically evaluated parameters, and study population. We then retrieved and reviewed full-text articles meeting the inclusion criteria according to the contents in the abstract. Next, we searched potentially concerned articles and reviewed their reference lists. Finally, we found a total of 198 eligible papers (Fig. 1). Of them, 102 papers were excluded because of irrelevance to the specific questions being asked or being not written in English. In addition, case reports and letters to the editor were excluded. After the exclusion, a total of 96 original papers were included in our review (Fig. 1).

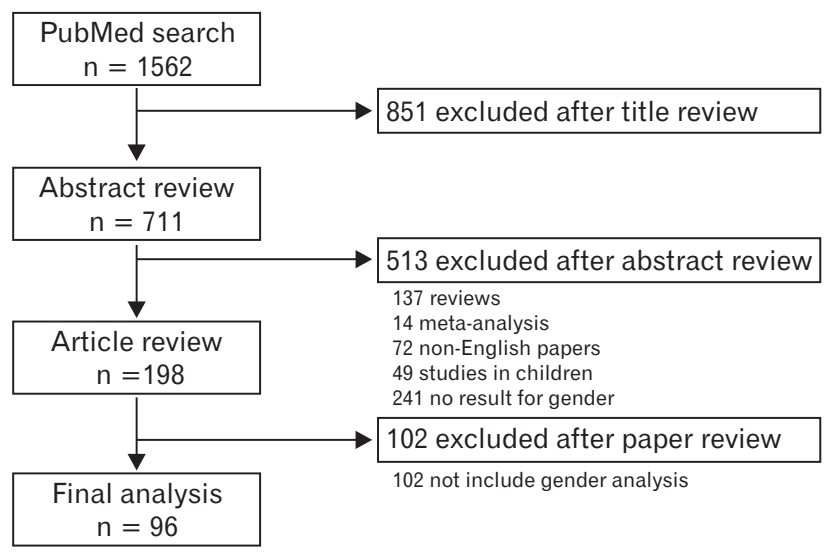

Figure 1. Flow chart documenting the results of search strategy. 


\section{Prevalence of Gastroesophageal Reflux} Disease

Global burden of GERD is increasing. ${ }^{16,17}$ However, the prevalence of GERD is different by country or research method. ${ }^{17,18}$ Furthermore, there are significant diversities in the distribution of GERD-related disorders (symptoms, reflux esophagitis, BE, and EAC) related to sex (Fig. 2). ${ }^{16}$ In this review we categorized these publications of GERD prevalence based on population or endoscopy-based study, and the prevalence of BE was separately introduced.

\section{Population-based Study}

Population-based research is regarded as suitable for GERD study because it is a common disease in the community. In addition, the diagnosis of GERD could be made based on symptoms. ${ }^{9,19}$ As GERD is not a serious disease, people do not always have to visit a hospital. ${ }^{20}$ According to a systematic review using the PubMed database between 1997 and 2011, the prevalence of GERD symptoms, majorly defined by weekly or frequent heartburn, did not differ between women and men $(19.4 \pm 2.3 \%$ vs $18.9 \pm 2.4 \%, P=$ 0.87 ) or between regions (US or Europe vs Asian countries, $P=$ $0.22)^{21}$

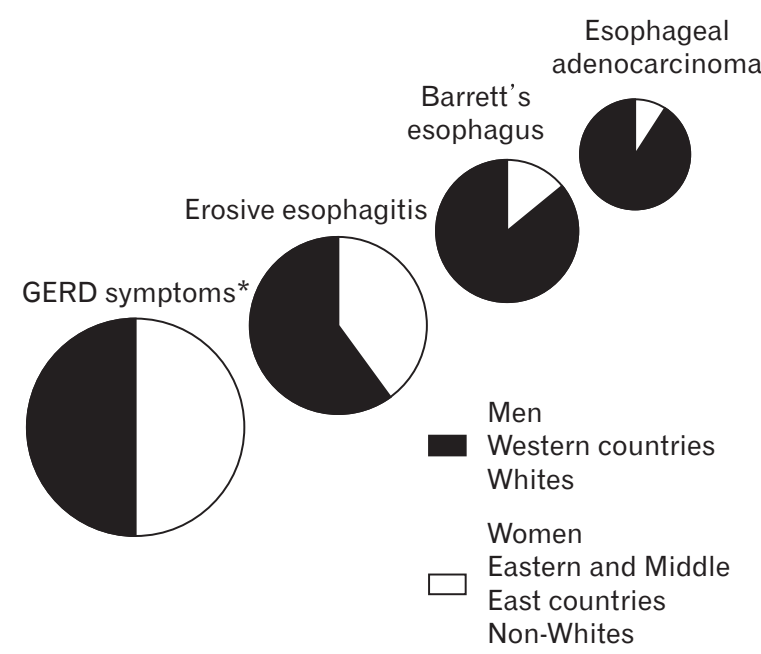

Figure 2. Schematic presentation of epidemiological trends in gastroesophageal reflux disease (GERD)-related disorders. While typical GERD symptoms are balanced between comparator groups, the distribution of complications becomes progressively skewed in gender, geographic and racial distribution. *GERD symptoms are similar between Western and Middle Eastern countries, but are lower in Eastern countries (adapted from Boeckxstaens et $\mathrm{al}^{16}$ ).
According to a survey performed in 2003 among dwellers aged 20 to 95 years in Olmsted County, ${ }^{22}$ the prevalence of GERD (defined as at least weekly heartburn and/or regurgitation) in the US was $18.1 \%$ (411/2273 individuals). There was no sex difference in the prevalence of GERD between men $(15 \%$; $95 \%$ confidence interval [CI], 12.9-17.3\%) and women (14\%; 95\% CI, 12.0-16.0\%) (Table). ${ }^{22}$

In a population-based study in Argentina (a representative geographical region of Latin America), there was no statistically significant difference in the prevalence of GERD according to sex. ${ }^{23}$ The prevalence of GERD was $9.5 \%$ (95\% CI, 7.5-11.5\%) in men and $14.1 \%$ (95\% CI, 9.6-16.4\%) in women, respectively $(P=0.21) .{ }^{23}$ In a Korean population-based study, the prevalence of GERD showed similar results. ${ }^{24}$ There was no significant difference in the prevalence of GERD (defined as heartburn and/or acid regurgitation experienced at least weekly) between the sexes of Koreans (3.5\% for men vs $3.5 \%$ for women). ${ }^{24}$ A study performed in South China also did not show difference in age-adjusted prevalence of GERD symptoms either between males and females $(2.6 \%$ vs $2.4 \%){ }^{25}$

\section{Endoscopy-based Study}

In contrast, many epidemiologic studies of GERD have shown that reflux esophagitis is more common in men than in women (Table). ${ }^{9,26-38}$ A meta-analysis has described that the men/women ratio in the prevalence of reflux esophagitis was 1.57 (95\% CI, 1.401.76) and the mean age of men with reflux esophagitis was lower than that of women. ${ }^{7}$

In a systematic review based on data of 67056 patients using the PubMed database between 1997 and 2011 (including 12 unbiased population-based studies, 8 studies from Asian countries, 2 studies from Europe, and 1 study from the US), the prevalence of reflux esophagitis was lower in women compared to that men (women: $6.1 \pm 1.6 \%$, range: $2.1-16.8 \%$; men: $15.9 \pm 2.5 \%$, range: $7.0-28.1 \% ; P<0.01)^{21}$

In contrast, NERD is more common in women. ${ }^{2,7,15,16,34,39}$ A quantitative analysis of esophageal symptoms has showed that the symptom frequency and severity were significantly higher in women than in men. ${ }^{8,36}$ On the other hand, the grade of esophagitis by esophagogastroduodenoscopy and the time period at $\mathrm{pH}$ below 4 during ambulatory 24-hour esophageal $\mathrm{pH}$ monitoring did not show any significant differences between men and women. ${ }^{8,36}$ In a multicenter study performed in Korea in 2006 with 25536 subjects who received esophagogastroduodenoscopic examination for medical check-up, the prevalence of reflux esophagitis was significantly higher in men $(11.2 \%)$ than in women $(3.1 \%)(P<0.0001){ }^{34}$ 
Table. Effect of Sex and Gender on Gastroesopahgeal Reflux Disease

\begin{tabular}{|c|c|c|}
\hline & Effect of sex and gender & References \\
\hline \multicolumn{3}{|l|}{ Prevalence } \\
\hline \multirow[t]{2}{*}{ Symptom-based population study } & Women $>$ men & 96 \\
\hline & Women $=$ men & $21-25$ \\
\hline \multicolumn{3}{|l|}{ Endoscopy-based study } \\
\hline Reflux esophagitis & Men $>$ women & $9,26-38$ \\
\hline NERD & Women $>$ men & $2,7,15,16,34,39$ \\
\hline Barrett's esophagus & Men $>$ women & $7,21,40-51$ \\
\hline \multicolumn{3}{|l|}{ Effect of aging } \\
\hline \multirow[t]{3}{*}{ Reflux esophagitis } & Increase with aging in both men and women: & $29,30,37,52$ \\
\hline & Age of women $>$ men & $29,30,37$ \\
\hline & Increase after menopause (after $50 \mathrm{~s}$ ) in women: & 29,30 \\
\hline \multirow[t]{2}{*}{ Barrett's esophagus } & Age of women $>$ men & $47-49$ \\
\hline & Increase after menopause (after 60s) in women: & 7,54 \\
\hline EAC & Age of women $>$ men & 57,59 \\
\hline \multicolumn{3}{|l|}{ Symptoms } \\
\hline Heartburn or regurgitation & More frequent in women $>$ men & 28,97 \\
\hline Extra-esophageal symptoms & Women $>$ men & $9,28,79$ \\
\hline Comorbid anxiety or depression & Women $>$ men & 79 \\
\hline \multicolumn{3}{|l|}{ Treatment } \\
\hline Response to PPIs & Men $>$ women & $110-114,116$ \\
\hline Dose escalation of PPIs & Women $>$ men & 115 \\
\hline \multirow[t]{2}{*}{ Postmenopausal HRT in women } & Increase the risk of gastroesophageal reflux symptoms & 123,125 \\
\hline & Reduced esophageal cancer risk & 120,121 \\
\hline
\end{tabular}

NERD, non-erosive reflux disease; EAC, esophageal adenocarcinoma; PPIs, proton pump inhibitors; HRT, hormone replacement therapy.

which was similar to the results in a 2011 nationwide multicenter study. ${ }^{30}$ Moreover, the degree of esophagitis was more severe in males than in females. ${ }^{34}$ However, the percentage of women having $\operatorname{NERD}(5 \%)$ was higher than that of men having NERD (3\%). ${ }^{2}$

With regard to risk factors for NERD or reflux esophagitis, a large scaled multicenter study using 25536 Korean subjects showed that sex was a risk factor for reflux esophagitis and NERD, oppositely. ${ }^{2}$ That is, considering risk factors for reflux esophagitis and NERD compared to normal population, men, alcohol, hiatal hernia, a history of Helicobacter pylori eradication, and body mass index $(\mathrm{BMI}) \geq 25 \mathrm{~kg} / \mathrm{m}^{2}$ were risk factors for reflux esophagitis. ${ }^{2}$ In contrast, females, smoking, age $<40$ and $\geq 60$ years vs. $40-59$ years, glucose $\geq 126 \mathrm{mg} / \mathrm{dL}, \mathrm{BMI}<23 \mathrm{~kg} / \mathrm{m}^{2}$, usage of antibiotics, a stooping posture at work, and a monthly income $<\$ 1000$ were risk factors for NERD. ${ }^{2}$ Similarly, a study with 10837 healthy Japanese adults (6332 men and 4505 women, aged 20-87 years) who received gastroesophagoduodenoscopy has revealed that men, older age, alcohol, smoking, no $H$. pylori infection, higher pepsinogen $\mathrm{I} / \mathrm{II}$ ratio in serum, and higher BMI were positively associated with reflux esophagitis. ${ }^{36}$ In contrast, women, younger age, smok- ing, alcohol, $H$. pylori infection, higher pepsinogen $\mathrm{I} / \mathrm{II}$ ratio in serum, and higher BMI were positively associated with NERD. ${ }^{36}$

\section{Prevalence of Barrett's Esophagus}

$\mathrm{BE}$ is defined as a change in the distal esophageal epithelium of any length characterized by metaplastic columnar epithelium. ${ }^{40}$ However, its histological criteria vary by country. The prevalence of BE is substantially diverse across studies as various results could be obtained due to difference in study design, population, and endoscopic biopsy protocols. ${ }^{32}$ The prevalence of BE was lower in women than in men (Table). ${ }^{7,19,40-51}$ A systematic review after analyzing the PubMed database between 1997 and 2011 has shown that the prevalence of $\mathrm{BE}$ was lower in women than in men (28 out of 10337 , range $0.03-4.6 \%$ vs 70 out of 12463 , range $0.08-8.2 \%$ ). ${ }^{21}$ In addition, a meta-analysis has demonstrated that the men/women ratio of $\mathrm{BE}$ was 1.71 (95\% CI, 1.42-2.04), without considering the presence of intestinal metaplasia. ${ }^{7}$ With regard to $\mathrm{BE}$ with intestinal metaplasia, the men/women ratio was 2.13 (95\% CI, 1.87-2.46). ${ }^{7}$ Studies from Asian countries have shown that the prevalence of $\mathrm{BE}$ was more common in men with a men/women ratio of ap- 
proximately 1.93-2.09..$^{40-45}$ In Korea, Choi et al ${ }^{44}$ reported that the prevalence of $\mathrm{BE}$ was $1.0 \%$ among 4002 subjects who received screening esophagogastroduodenoscopy. Significant risk factors of $\mathrm{BE}$ were men, old age, acid regurgitation symptom, and smoking. ${ }^{44}$ Similarly, another Korean nationwide prospective multicenter study has shown that the prevalence of $\mathrm{BE}$ was $0.84 \%$ in 25536 health check-up adults. ${ }^{51}$ The risk factors for BE were men (OR, 1.82; 95\% CI, 1.32-2.50), hiatal hernia (OR, 5.66; 95\% CI, 3.70-8.66), age $>60$ compared to age $<40(\mathrm{OR}, 1.81 ; 95 \% \mathrm{CI}, 1.07-3.09)$, and nonsteroidal anti-inflammatory drug use (OR, 2.02; 95\% CI, 1.28-3.20) based on multivariate analysis. ${ }^{51}$

\section{Effect of Aging on the Prevalence of Gastroesophageal Reflux Disease or Barrett's Esophagus in Women}

A close relation between women's reproductive hormones and the severity and prevalence of GERD has been reported (Table). During the postmenopausal period, the prevalence of the GERD spectrum rises rapidly. However, it is lower than that in men during the reproductive age. ${ }^{15}$ In a large endoscopy-based study performed in the $\mathrm{UK}^{29}$ the mean ages of men and women with reflux esophagitis were $59.7 \pm 16.1$ and $64.4 \pm 15.1$ years, respectively. Several studies have also suggested that the incidence of reflux esophagitis increased with aging, with women having the trend to be older than men. ${ }^{29,30,37,52}$ Moreover, older women showed more severe reflux esophagitis than older men and the incidence of severe reflux esophagitis tends to be increased higher in postmenopausal women than in men. ${ }^{29,30}$ Another endoscopy-based study has reported that the incidence of reflux esophagitis was increased in women after the age of 50 years. ${ }^{29}$ The incidence of reflux esophagitis in women was similar to that in men by the age of 80 years. ${ }^{29}$

A recent Japanese study using 7670 study subjects (5166 men and 2504 women) who visited a medical center for health check-up has investigated gender differences related to chronological changes in BMI and the prevalence of reflux esophagitis. ${ }^{53}$ Multiple logistic regression analysis has revealed that larger hiatal hernia, high BMI, mild gastric mucosal atrophy, and older age were significant positive predictive factors for the presence of reflux esophagitis in both men and women. ${ }^{53}$ The number of men with reflux esophagitis and high BMI has increased during the 10 -year examination period. ${ }^{53}$ However, the number of women with reflux esophagitis and high BMI has not increased. ${ }^{53}$ The percentage of subjects with large hiatal hernias and mild gastric mucosal atrophy were increased in both men and women during the 10 -year period. ${ }^{53}$ These results suggest that a lack of change in BMI might be a crucial factor for the constant prevalence of reflux esophagitis in Japanese women. ${ }^{53}$

In terms of $\mathrm{BE}$, the mean age of women with $\mathrm{BE}$ has been reported to be significantly higher than that of men with $\mathrm{BE}$ (65.5 \pm 15.0 years vs $59.3 \pm 13.8$ years, $P<0.01)$ in a large cohort study performed in the Netherlands. ${ }^{54}$ Other studies have also demonstrated that the prevalence of $\mathrm{BE}$ in women begin to rise after 60 years of age. ${ }^{7,54}$ The increment of the prevalence of $\mathrm{BE}$ in women during the postmenopausal period has exceeded that in men. ${ }^{7,55}$ Age-specific increases in BE in parallel with a 20-year age shift between men and women have also been reported. ${ }^{54,56}$

With regard to EAC, 17 years of delay in age-specific incidence has been reported in women compared to that in men in a recent study. These results might be due to the disappearance of the protective effect of female sex hormones in postmenopausal women. ${ }^{57}$

\section{Pathophysiology}

\section{Role of Estrogen}

GERD is influenced by multiple factors, including gastric acid secretion, hiatal hernia, lower esophageal sphincter function, esophageal motility, esophageal nociception, and others. ${ }^{7,16,17,58} \mathrm{~A}$ male-predominant gender bias including reflux esophagitis, BE, and EAC allude to sex and gender differences in the vulnerability or resistance of the esophageal epithelium to caustic compounds of gastroduodenal contents. ${ }^{16,59}$ Decreased estrogen after menopause might be related with the rise in the incidence and severity of reflux esophagitis (Fig. 3). 16,60 However, the detailed mechanism of estrogen in controlling the pathogenesis of GERD spectrum remains unclear.

\section{Immune Response}

In experimental animal models, females have been less injured than males by gastric inflammation in response to chemical substances or bacterial infection. ${ }^{60,61}$ Sometimes, these chemical insults and bacterial infections resulted in a difference in male predominant carcinogenesis. ${ }^{61}$ Estrogen has been revealed to have anti-inflammatory activity which contributes to tissue resistance in females in animal models. ${ }^{10,61}$ Recently, Masaka et $\mathrm{al}^{10}$ explored the role of estrogen (E2) in protecting esophageal damage in a chronic rat reflux esophagitis model. In addition, a significant male-predominance in esophageal tissue damage by exogenous nitric oxide (NO) has been found. ${ }^{10}$ In male rats, severe esophageal ulcers and inflammation with polymorphonuclear cell and lymphocyte infiltrates have been induced by exogenous NO. However, only mild tissue dam- 


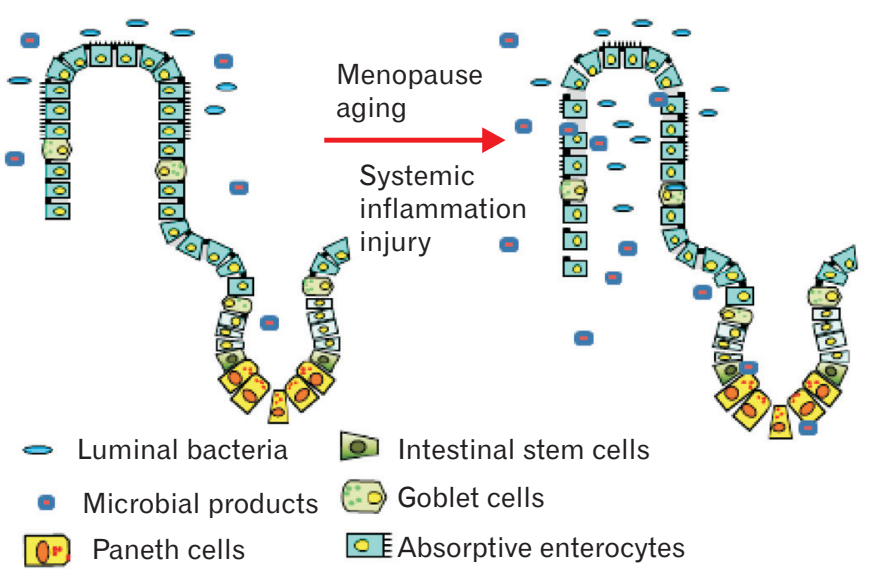

age has been observed in female rats. ${ }^{10}$ Furthermore, exogenous $17 \beta$-estradiol binding and signaling through E2 receptors attenuated esophageal tissue damage in males and ovariectomized rats through reducing mast cell-mediated cytotoxicity and the production of cytokines, specifically TNF- $\alpha$ that drives inflammation. ${ }^{10} \mathrm{In}$ contrast, treatment with $17 \alpha$-estradiol that binds $\mathrm{E} 2$ receptors but does not induce downstream signaling has no effect on tissue damage. ${ }^{10}$ While esophageal damage was more severe in ovariectomized rats compared to sham ovariectomized rats, the aggravated esophageal damage could be weakened by $17 \beta$-estradiol..$^{10}$ Furthermore, aggravated esophageal damage in male rats could be reduced by $17 \beta$-estradiol. ${ }^{10}$ Interestingly, estrogen can significantly suppress the levels of the esophageal macrophage inhibitory factor. ${ }^{6}$ Because estrogen can target the tissue macrophage inhibitory factor to promote wound healing by inactivating macrophages, it is suggested that this anti-inflammatory role associated with estrogen has contributed to sex and gender differences in GERD. ${ }^{10,62}$

\section{Esophageal Epithelial Barrier Function}

The esophageal barrier function is important for the protection against reflux substance in GERD. ${ }^{13,60,63}$ Chronic exposure to gastric acid and other intra-esophageal materials such as bile and alcohol can disrupt the esophageal barrier function. ${ }^{63,64}$ Reduced levels of E2 due to aging, especially, after women's menopause, can potentially increase epithelial permeability and microbial translocation (Fig. 3). ${ }^{60}$ Recent studies also suggested that estrogen can increase esophageal mucosal resistance by up-regulating the expression of esophageal tight junction protein such as occludin. Such a mechanism of estrogen might explain the male predominance of GERD ${ }^{63-65}$ Honda et $\mathrm{al}^{63}$ conducted an animal study to identify the role of estrogen treatment on the esophageal epithelial barrier function and found that $17 \beta$-estradiol administration reduced

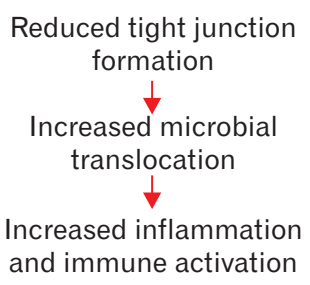

Figure 3. Schematic of the proposed effects of aging and hormonal changes. Proposed mechanism of the loss of mucosal epithelial integrity and microbial translocation and the effects of hormonal changes associated with aging. Reduced levels of E2 due to aging, especially, after women's menopause, can potentially increase epithelial permeability and microbial translocation (adapted from Grishina et $\mathrm{al}^{60}$ ).

the dilation of the intercellular space caused by luminal irritants. Moreover, 17 $\beta$-estradiol administration increased the expression of occludin..$^{63}$ Adhesion between esophageal neighboring cells could be enhanced by estrogen which can potentiate the expression of the integral tight junction protein. ${ }^{65}$ Lack of these protective effects of estrogen in men could possibly explain the higher prevalence of reflux esophagitis in men than in women. ${ }^{63}$ Further studies are needed to understand the function of estrogen and junctional proteins and downstream signals in detail.

\section{Esophageal Nociception}

The understanding about how heartburn is experienced has been greatly improved with the detection of transient receptor potential vanilloid subfamily member-1 receptors (TRPV1) in esophageal mucosa. ${ }^{65,66}$ TRPV1 may lead to visceral hypersensitivity as one of the important factors in the pathogenesis of NERD. ${ }^{67}$ It has been hypothesized that TRPV1 activation could trigger inflammation by releasing substance $\mathrm{P}$ and calcitonin-gene-related peptide in primary afferent neurons. ${ }^{68}$ Therefore, up-regulation of TRPV1 expression in the esophageal mucosa might be the underlying mechanism of the visceral hypersensitivity in NERD. ${ }^{66}$

Several studies have shown that the expression levels of esophageal mucosal TRPV1 are more increased in patients with GERD than those in patients without GERD, and that the expression of esophageal TRPV1 in NERD was higher than that in reflux esophagitis. ${ }^{69-71}$

In contrast, a study on Koreans has shown that not only the levels of TRPV1, but also the levels of glial cell line-derived neurotrophic factor, nerve growth factor, proteinase-activated receptor 2 (PAR2), and IL-8 at mRNA level were the highest in the reflux esophagitis group, followed by those in NERD and control groups. ${ }^{72}$ The differences in these expression levels between the 
control and reflux esophagitis groups were statistically significant. $^{72}$ Interestingly, up-regulation of the TRPV1 and PAR2 pathways played a role in the development of distal esophageal inflammation and reflux symptoms, but not in the extra-esophageal reflux symptoms. $^{72}$

In addition, TRPV1 has been proposed as a possible mechanism involved in the manifestation of gastrointestinal symptoms. ${ }^{70,72-75}$ TRPV1 activation in primary afferent neurons evoked the burning sensation, as well as inducing inflammatory and neuroinflammatory effects, hence causing GERD. ${ }^{69,74}$ Further studies are needed to evaluate the mechanistic importance in the relationship between estrogen and esophageal TRPV1 expression.

\section{Gender Difference in Esophageal Acid Exposure}

Ambulatory 24-hour esophageal $\mathrm{pH}$ monitoring is the gold standard method to evaluate esophageal acid exposure. ${ }^{5,76,77}$ There are gender-related differences in esophageal acid exposure among men and women. ${ }^{76}$ Women have significantly fewer reflux events at both esophageal measuring spots, and significantly less total reflux time and percentage of time with $\mathrm{pH}<4$ in a study for subjects without reflux symptoms or GERD ${ }^{76}$ These results have implications with regard to men's higher prevalence of $\mathrm{BE}$ than women while women have lower esophageal acid exposure in comparison to men. $^{76}$

\section{Psychological Factors}

Previous epidemiological surveys have shown that psychological factors play an important part in the pathogenesis of GERD. ${ }^{78}$ Psychological stress increased the perception of heartburn and aggravated GERD symptoms. ${ }^{79,80}$ Fass et al ${ }^{81}$ have shown that acute stress can enhance the sensitivity to intraesophageal acid perception in both reflux esophagitis or NERD patients. They also demonstrated that the increased perceptual responses to acid was related to greater emotional response to the stress factor. ${ }^{81}$

Previous reports have revealed that low quality of life (QOL) was severe in patients with extra-esophageal symptoms. ${ }^{82,83}$ The QOL of patients with GERD was associated with psychological factors, including symptoms and mental factors. ${ }^{84} \mathrm{~A}$ recent study with 217 Korean subjects has shown that sleep dysfunction and anxiety were higher and QOL was low in patients with GERD, especially in patients with NERD ${ }^{84}$ In addition, the GERD impact scale score was higher in the NERD group $(9.2 \pm 0.4)$ than that in the reflux esophagitis group $(6.5 \pm 0.3)(P<0.001))^{82}$ Furthermore, interruption in daily life was more severe in the NERD group than that in the reflux esophagitis group. Anxiety subscales of hospital anxiety and depression scale scores were higher in NERD and reflux esophagitis groups compared to those in the control group. ${ }^{84}$

In NERD, visceral hypersensitivity is an important pathophysiological mechanism. Three possible mechanisms are associated with visceral hypersensitivity: peripheral sensitization, central sensitization, and psychoneuroimmune interactions. ${ }^{67,85-87}$ Fass and Tougas ${ }^{88}$ have suggested that pathologic or physiologic intraesophageal stimuli may result in symptoms of NERD. Their study has highlighted the role of central (through brain-gut interactions) and peripheral (not esophageal) mechanisms in regulating perception of intraesophageal stimuli. ${ }^{88}$

Depression and anxiety are more common in women than in men in the general population. ${ }^{88-90}$ The prevalence of NERD is also more common in women. Accordingly, comorbid depression and anxiety may play a role to the increased symptom burden in women. ${ }^{79}$ Women might have different symptoms and physical signs of diseases due to differences in afferent signals, hormone levels, and GERD severity. ${ }^{89-92}$ However, limited studies are available regarding sex and gender differences in psychological factors associated with GERD.

\section{Symptoms}

Symptoms of GERD can be subdivided into esophageal symptoms (such as heartburn and regurgitation) and extra-esophageal symptoms (such as chronic cough, chest pain, hoarseness, and globus sensation in the throat). ${ }^{1,8,16,93-95}$

Whether extra-esophageal reflux symptoms are truly related to esophageal reflux remains controversial. A recent study has shown that the presence of reflux symptoms is related to significantly higher levels of TRPV1, PAR2, and IL-8. ${ }^{72}$ Notably, not extraesophageal reflux symptoms, but esophageal reflux symptoms, are significantly associated with them. ${ }^{72}$ These results suggest that the pathophysiology of extra-esophageal reflux symptoms might be different from that of esophageal reflux symptoms. ${ }^{72}$ That is, extraesophageal reflux symptoms might not be due to direct sensitization at the distal esophagus, but due to indirect mechanisms involving vagally-mediated reflex from acid exposure on the distal esophagus. In addition, up-regulation of inflammation-related genes might be located in other areas such as the proximal esophagus or pharynx. ${ }^{72}$ Many studies have shown significant difference in symptom expression between women and men with GERD. ${ }^{8}$ 


\section{Esophageal Symptoms and Sex/Gender}

In a population-based study performed in Iran using the most commonly accepted GERD definition (either heartburn or acid regurgitation), female gender (OR, 1.55), NSAID use (OR, 4.23), smoking $(\mathrm{OR}, 1.83), \mathrm{BMI}>30 \mathrm{~kg} / \mathrm{m}^{2}(\mathrm{OR}, 1.79)$, less education (OR, 1.52), and GERD in spouse (OR, 1.82) were associated with frequent GERD based on multivariable analysis. ${ }^{96}$

A recent population-based telephone survey performed in Brazil has shown that women have reported significantly higher frequencies ( $>1.5$-fold) of symptoms corresponding with GERD (occurring at least twice per week), including heartburn $(P=$ $0.047)$, a burning sensation in the stomach $(P=0.012)$, acid regurgitation $(P<0.001)$, swallowing difficulty $(P=0.012)$, or pain on swallowing $(P=0.009)$ compared to men (Table). ${ }^{97}$ Another study showed that quantitative esophageal symptom scores for heartburn, regurgitation, belching, and nocturnal symptoms which had been analyzed by endoscopy, ambulatory $\mathrm{pH}$, and esophageal manometry, were significantly higher in women than in men. ${ }^{8}$ Women have also reported higher symptom scores of lower abdominal symptoms such as diarrhea, abdominal pain, and constipation $(P<0.01){ }^{8}$ These results imply that gender difference might exist in symptom perception and reporting of symptoms. ${ }^{8}$

\section{Extra-esophageal Symptoms and Sex/Gender}

The ProGerd study performed in patients with GERD has shown that there are gender differences in extra-esophageal symptoms between women and men (Table). Extra-esophageal symptoms were found to be significantly more common in women than in men $(\mathrm{OR}, 1.15$; 95\% CI, 1.03-1.30; $P<0.0178) .{ }^{28}$ Another study evaluated esophageal pain threshold using balloon inflation for asymptomatic volunteers, and also found significant difference in results between men and women. ${ }^{98}$ Women have a significantly lower pain threshold on the basis of volume or distention compared to men. However, there is no significant difference in body size or esophageal luminal diameters between men and women, suggesting that the difference in pain sensitivity between men and women might be due to other factors. ${ }^{98}$ Further studies are warranted to elucidate the mechanisms responsible for such sex and gender differences in pain sensitivity.

Differential sensitivity and enhanced symptoms in women are regarded to have diagnostic and therapeutic implications. ${ }^{8}$ Usually, women seek earlier medical treatment and receive proper therapy in the course of GERD. Therefore, they may not develop complications such as BE or EAC. ${ }^{8}$ Furthermore, women have differential responses to therapy for GERD, or tend to seek the interventions such as endoscopic therapy or surgery more often than men. ${ }^{8}$

Recently, Vakil et $\mathrm{al}^{79}$ studied partial responders of proton pump inhibitors (PPIs) and found that the Reflux Symptom Questionnaire 7-day recall domain scores for heartburn, burping and hoarseness, cough and swallowing difficulty, and the Gastrointestinal Symptom Rating Scale domain discomfort scores for abdominal pain, indigestion, and constipation in women were significantly higher than those in men (all $P<0.05$ ). In addition, comorbid anxiety and depression in women were more frequent than those in men. $^{79}$

\section{Gender and Healthcare Seeking}

Even though similar results were found in the number of men or women getting medical advice for GERD, women seem more likely to visit physicians more often. ${ }^{18,52,99-103}$ This might be caused by the higher possibility of diagnostic testing to evaluate symptoms of GERD that are not fully explained by mucosal changes such as less prevalent esophagitis or BE in women. A population-based study on GERD in south China has shown similar results. ${ }^{52}$ That is, women were an independent factor related to health care-seeking behavior $(P<0.001)$, frequency of heartburn $(P=0.032)$, degree of depression $(P=0.004)$, and social morbidity $(P<0.001){ }^{52}$

\section{Treatment}

Understanding sex and gender-related differences in GERD is important for gender-related biological factors which might provide better treatment strategy for both men and women.

\section{Sex/Gender and Treatment Response}

Treatment of GERD includes lifestyle modification and medications. ${ }^{104,105}$ PPIs are the most effective medicines for treating GERD. ${ }^{106}$ Therefore, patients with GERD are frequently treated with PPIs. ${ }^{107,108}$ However, 17-32\% of patients with GERD experienced persistent and troublesome heartburn or regurgitation despite standard-dose PPI treatment. In addition, the majority experienced refractory symptoms at higher doses. ${ }^{5,109}$ Several studies have shown that there are gender differences in the prevalence of partial response to PPIs (Table). ${ }^{79,110-113}$ In a study conducted in patients newly diagnosed with GERD in primary care clinics, partial symptomatic response to PPI therapy was found to be related to women (OR, 1.20; 95\% CI, 1.05-1.37). ${ }^{111}$ In a systemic review, persistent GERD symptoms despite PPI treatment were more likely to be revealed in women than in men (risk ratio $[\mathrm{RR}]: 3.66 ; P<0.001) .{ }^{110}$ 
In another study performed in patients with reflux esophagitis and frequent heartburn, men were found to be more likely to have improvement in heartburn than women (OR, 1.35; 95\% CI, 1.14-1.59; $P<0.001) .{ }^{114} \mathrm{~A}$ recent Korean GERD study regarding predictive factors of response to PPI has shown that BMI $<23 \mathrm{~kg} / \mathrm{m}^{2}$ (OR, 2.20 ; 95\% CI, 1.12-4.34), history of psychotherapy or neuropsychiatric medication (OR, 2.44; 95\% CI, 1.23-4.85), higher total Pittsburgh sleep quality index score (OR, 1.20; 95\% CI, 1.05-1.35), and NERD (OR, 3.30; 95\% CI, 1.54-7.11) was related to poor response to PPIs. ${ }^{107}$ However, gender did not have a statistically significant association with PPI therapy response. ${ }^{107}$

However, female gender is associated with requiring dose escalation of PPIs for treatment. ${ }^{113}$ In a post hoc analysis using 5-year data from patients in the LOTUS trial who were randomized to take esomeprazole at $20 \mathrm{mg}$ once daily, female sex, smoking, absence of $H$. pylori infection, a long duration of GERD history, and high supine baseline acid reflux into the esophagus was related to increased possibility of requiring dose escalation to esomeprazole at $40 \mathrm{mg}$ daily (all $P<0.05$ ). ${ }^{115}$

Forecasting the success of PPI therapy for symptomatic GERD patients would contribute to preventing empiric PPI drug attempts or repeating additional tests, thus reducing health care costs. ${ }^{116}$ Several recent studies have suggested that women, lower BMI, and psychologic disorders such as anxiety and depression was related to poor response to PPI therapy in patients with GERD, ${ }^{112,117}$ while men, obesity, typical reflux symptoms such as heartburn and regurgitation, and alcohol consumption was related to positive therapeutic responses to PPIs in a retrospective study of 683 subjects suspected of GERD who underwent $\mathrm{pH}$-metry/ impedance measurement $(\mathrm{pH} / \mathrm{MII}) .{ }^{116}$ It has been suggested that $\mathrm{pH} / \mathrm{MII}$ (including evaluation of the symptom index) instead of empiric PPI therapy should be considered in non-obese women with atypical reflux symptoms. ${ }^{116}$ However, response rates and associated factors for PPI treatment could be different according to study population and study design. ${ }^{107}$

\section{Hormone Replacement Therapy}

It has been shown that estrogen has an anti-inflammatory action that can modulate immune cell activity such as cell activation and proliferation, cytokine production, and wound healing. ${ }^{12,60}$ Systemic and topical estrogen treatment are related to promotion of cutaneous wound healing compared to age-matched controls in studies on postmenopausal women. ${ }^{118,119}$ These results raise the possibility that estrogen might be used as a medication for GERD treatment due to its protective function. ${ }^{120}$
Estrogen replacement in postmenopausal women might potentially confer a protective effect against esophageal cancer by reducing the extent of esophageal injury caused by gastric acid, thus decreasing the risk of $\mathrm{BE}$ and $\mathrm{EAC} .{ }^{120} \mathrm{~A}$ recent case control cohort study performed in UK has shown that reduced esophageal cancer risk is associated with prolonged hormone replacement therapy (HRT) for 5-10 years (hazard ratio [HR], 0.25; 95\% CI, 0.070.95 ) and time-dependent covariate with increasing duration of HRT use (HR, 0.06; 95\% CI, 0.01-0.43) (Table). ${ }^{120}$ In a metaanalysis, risks for HRT use vs. never use of HRT significantly decreased for esophageal cancers (RR, 0.68; 95\% CI, 0.55-0.84; $P<0.001$ ) (Table). ${ }^{121}$ However, a population-based retrospective cohort study for men who were exposed to quite a lot of estrogen has shown that there is no reduction in the risk of EAC by estrogen treatment. ${ }^{110}$ The role of estrogen as an anti-inflammatory agent remains uncertain. Further studies are needed to determine the potential role of hormonal factors in the pathogenesis of EAC to understand the importance of gender difference. ${ }^{120}$

On the other hand, it has been suggested that female sex hormones can increase the risk of gastroesophageal reflux symptoms by relaxing the lower esophageal sphincter via $\mathrm{NO}^{122-124}$ A populationbased study demonstrated a positive correlation between reflux symptoms and postmenopausal HRT use. ${ }^{125}$ The risk of reflux symptoms is significantly increased among severely obese (BMI $\left.>35 \mathrm{~kg} / \mathrm{m}^{2}\right)$ men (OR, 3.3; 95\% CI, 2.4-4.7) and women (OR, $6.3 ; 95 \% \mathrm{CI}, 4.9-8.0)$ compared to those with BMI $<25 \mathrm{~kg} / \mathrm{m}^{2}$. The correlation between BMI and reflux symptoms was stronger $(P<0.001)$ in premenopausal women compared to that in postmenopausal women. The use of postmenopausal hormone therapy increased the strength of the association $(P<0.001) .{ }^{125}$ For women with normal body weight, a weak association between hormone therapy and reflux symptoms has been found. ${ }^{125} \mathrm{BMI}$ reduction is positively associated with decreased risk of reflux symptoms. ${ }^{125}$ The association between hormone therapy and reflux symptoms is stronger with increasing BMI, implying that estrogen replacement is an effective modifier of the association between BMI and reflux symptoms. ${ }^{125}$ Further studies are warranted to determine whether HRT is associated with GERD symptoms or esophageal injury that leads to EAC.

\section{Conclusions}

Reflux symptoms and NERD affect women more than men. However, men suffer pathologic changes more frequently. Women have higher mean age (such as postmenopausal period) of cancer 
incidence than men, suggesting a role of estrogen in delaying the onset of BE and EAC. Anti-inflammatory action of estrogen and esophageal epithelial resistance against refluxate are likely to be associated with the sex and gender differences in GERD spectrum between men and women. In terms of GERD symptoms, women are more likely to have heartburn, regurgitation, belching, and extra-esophageal symptoms than men. These results imply that sex and gender play a role in symptom nociception. Differential sensitivity and enhanced symptoms reported by women might have diagnostic and therapeutic implications. The role of estrogen as an anti-inflammatory agent remains intriguing. Further studies are warranted to determine the role of estrogen in the pathogenesis of EAC. Differential disease recognition and medical care for sex and gender should be taken into account in the GERD spectrum.

Financial support: This research was supported by Support Program for Women in Science, Engineering and Technology through the National Research Foundation of Korea (NRF) funded by the Ministry of Science, ICT and Future Planning (Grant No. 2016H1C3A1903202).

\section{Conflicts of interest: None.}

Author contributions: Nayoung Kim: conception and design, and final approval of the version to be published; and Young Sun Kim and Gwang Ha Kim: drafting the article or revising it critically for important intellectual content.

\section{References}

1. Vakil N, van Zanten SV, Kahrilas P, Dent J, Jones R; Global Consensus Group. The Montreal definition and classification of gastroesophageal reflux disease: a global evidence-based consensus. Am J Gastroenterol 2006;101:1900-1920.

2. Kim N, Lee SW, Cho SI, et al. The prevalence of and risk factors for erosive oesophagitis and non-erosive reflux disease: a nationwide multicentre prospective study in Korea. Aliment Pharmacol Ther 2008;27:173-185.

3. Aziz Q, Fass R, Gyawali CP, Miwa H, Pandolfino JE, Zerbib F. Functional esophageal disorders. Gastroenterology Published Online First: 15 Feb 2016. doi: 10.1053/j.gastro.2016.02.012.

4. Chen CL, Hsu PI. Current advances in the diagnosis and treatment of nonerosive reflux disease. Gastroenterol Res Pract. 2013;2013:653989.

5. Khan MQ, Alaraj A, Alsohaibani F, Al-Kahtani K, Jbarah S, Al-Ashgar $\mathrm{H}$. Diagnostic utility of impedance-pH monitoring in refractory nonerosive reflux disease. J Neurogastroenterol Motil 2014;20:497-505.

6. de Bortoli N, Martinucci I, Bellini M, et al. Overlap of functional heartburn and gastroesophageal reflux disease with irritable bowel syndrome.
World J Gastroenterol 2013:19:5787-5797.

7. Ford AC, Forman D, Reynolds PD, Cooper BT, Moayyedi P. Ethnicity, gender, and socioeconomic status as risk factors for esophagitis and Barrett's esophagus. Am J Epidemiol 2005;162:454-460.

8. Lin M, Gerson LB, Lascar R, Triadafilopoulos G. Features of gastroesophageal reflux disease in women. Am J Gastroenterol 2004;99:14421447.

9. Mishima I, Adachi K, Arima N, et al. Prevalence of endoscopically negative and positive gastroesophageal reflux disease in the Japanese. Scand J Gastroenterol 2005;40:1005-1009.

10. Masaka T, Iijima K, Endo H, et al. Gender differences in oesophageal mucosal injury in a reflux oesophagitis model of rats. Gut 2013;62:6-14.

11. Wizemann TM, Pardue ML. Exploring the biological contributions to human health: does sex matter? Washington, DC: National Academies Press, 2001.

12. Chang L, Toner BB, Fukudo S, et al. Gender, age, society, culture, and the patient's perspective in the functional gastrointestinal disorders. Gastroenterology 2006;130:1435-1446.

13. Annandale E, Hammarström A. Constructing the 'gender-specific body': a critical discourse analysis of publications in the field of genderspecific medicine. Health (London) 2011;15:571-587.

14. Kilminster S, Downes J, Gough B, Murdoch-Eaton D, Roberts T. Women in medicine-is there a problem? A literature review of the changing gender composition, structures and occupational cultures in medicine. Med Educ 2007;41:39-49.

15. Asanuma K, Iijima K, Shimosegawa T. Gender difference in gastroesophageal reflux diseases. World J Gastroenterol 2016;22:1800-1810.

16. Boeckxstaens G, El-Serag HB, Smout AJ, Kahrilas PJ. Symptomatic reflux disease: the present, the past and the future. Gut 2014;63:11851193.

17. El-Serag HB, Sweet S, Winchester CC, Dent J. Update on the epidemiology of gastro-oesophageal reflux disease: a systematic review. Gut 2014;63:871-880.

18. Jung HK. Epidemiology of gastroesophageal reflux disease in Asia: a systematic review. J Neurogastroenterol Motil 2011;17:14-27.

19. Zavala-Gonzales MA, Azamar-Jacome AA, Meixueiro-Daza A, et al. Validation and diagnostic usefulness of gastroesophageal reflux disease questionnaire in a primary care level in Mexico. J Neurogastroenterol Motil 2014;20:475-482.

20. Kitchin LI, Castell DO. Rationale and efficacy of conservative therapy for gastroesophageal reflux disease. Arch Intern Med 1991;151:448454.

21. Nusrat S, Nusrat S, Bielefeldt K. Reflux and sex: what drives testing, what drives treatment? Eur Gastroenterol Hepatol 2012;24:233-247.

22. Jung HK, Halder S, McNally M, et al. Overlap of gastro-oesophageal reflux disease and irritable bowel syndrome: prevalence and risk factors in the general population. Aliment Pharmacol Ther 2007;26:453-461.

23. Chiocca JC, Olmos JA, Salis GB, et al. Prevalence, clinical spectrum and atypical symptoms of gastro-oesophageal reflux in Argentina: a nationwide population-based study. Aliment Pharmacol Ther 2005;22:331342.

24. Cho YS, Choi MG, Jeong JJ, et al. Prevalence and clinical spectrum of 
gastroesophageal reflux: a population-based study in Asan-si, Korea. Am J Gastroenterol 2005;100:747-753.

25. Chen M, Xiong L, Chen H, Xu A, He L, Hu P. Prevalence, risk factors and impact of gastroesophageal reflux disease symptoms: a populationbased study in south China. Scand J Gastroenterol 2005;40:759-767.

26. El-Serag HB, Johanson JF. Risk factors for the severity of erosive esophagitis in Helicobacter pylori-negative patients with gastroesophageal reflux disease. Scand J Gastroenterol 2002;37:899-904.

27. Nilsson M, Lundegårdh G, Carling L, Ye W, Lagergren J. Body mass and reflux oesophagitis: an oestrogen-dependent association? Scand J Gastroenterol 2002;37:626-630.

28. Jaspersen D, Kulig M, Labenz J, et. al. Prevalence of extra-oesophageal manifestations in gastro-oesophageal reflux disease: an analysis based on the ProGERD Study. Aliment Pharmacol Ther 2003;17:1515-1520.

29. Menon S, Jayasena H, Nightingale P, Trudgill NJ. Influence of age and sex on endoscopic findings of gastrooesophageal reflux disease: an endoscopy database study. Eur J Gastroenterol Hepatol 2011;23:389-395.

30. Furukawa N, Iwakiri R, Koyama T, et al. Proportion of reflux esophagitis in 6010 Japanese adults: prospective evaluation by endoscopy. J Gastroenterol 1999;34:441-444.

31. Koike T, Ohara S, Sekine H, et al. Helicobacter pylori infection inhibits reflux esophagitis by inducing atrophic gastritis. Am J Gastroenterol 1999;94:3468-3472.

32. Ho KY, Chan YH, Kang JY. Increasing trend of reflux esophagitis and decreasing trend of Helicobacter pylori infection in patients from a multiethnic Asian country. Am J Gastroenterol 2005;100:1923-1928.

33. Seo GS, Jeon BJ, Chung JS, et al. The prevalence of erosive esophagitis is not significantly increased in a healthy Korean population - could it be explained?: a multi-center prospective study. J Neurogastroenterol Motil 2013;19:70-77.

34. Shim KN, Hong SJ, Sung JK, et al. Clinical spectrum of reflux esophagitis among 25,536 Koreans who underwent a health check-up: a nationwide multicenter prospective, endoscopy-based study. J Clin Gastroenterol 2009;43:632-638.

35. Lee JH, Kim N, Chung IK, et al. Clinical significance of minimal change lesions of the esophagus in a healthy Korean population: a nationwide multi-center prospective study. J Gastroenterol Hepatol 2008;23(7 Pt 1):1153-1157.

36. Minatsuki C, Yamamichi N, Shimamoto T, et al. Background factors of reflux esophagitis and non-erosive reflux disease: a cross-sectional study of 10,837 subjects in Japan. PLoS One 2013;8:e69891.

37. Moki F, Kusano M, Mizuide M, et al. Association between reflux esophagitis and features of the metabolic syndrome in Japan. Aliment Pharmacol Ther 2007;26:1069-1075.

38. Peng S, Cui Y, Xiao YL, et al. Prevalence of erosive esophagitis and Barrett's esophagus in the adult Chinese population. Endoscopy 2009;41:1011-1017.

39. Ronkainen J, Aro P, Storskrubb T, et al. High prevalence of gastroesophageal reflux symptoms and esophagitis with or without symptoms in the general adult Swedish population: a Kalixanda study report. Scand J Gastroenterol 2005;40:275-285.

40. Wang KK, Sampliner RE; Practice Parameters Committee of the
American College of Gastroenterology. Updated guidelines 2008 for the diagnosis, surveillance and therapy of Barrett's esophagus. Am J Gastroenterol 2008;103:788-797.

41. Dong Y, Qi B, Feng XY, Jiang CM. Meta-analysis of Barrett's esophagus in China. World J Gastroenterol 2013;19:8770-8779.

42. Chen X, Zhu LR, Hou XH. The characteristics of Barrett's esophagus: an analysis of 4120 cases in China. Dis Esophagus 2009;22:348-353.

43. Chang CY, Lee YC, Lee CT, et al. The application of Prague $\mathrm{C}$ and $\mathrm{M}$ criteria in the diagnosis of Barrett's esophagus in an ethnic Chinese population. Am J Gastroenterol 2009;104:13-20.

44. Choi CY, Suh S, Park JS, et al. [The prevalence of Barrett's esophagus and the comparison of Barrett's esophagus with cardiac intestinal metaplasia in the health screening at a secondary care hospital.] Korean J Gastroenterol 2012;60:219-223. [Korean]

45. Kim JH, Rhee PL, Lee JH, et al. Prevalence and risk factors of Barrett's esophagus in Korea. J Gastroenterol Hepatol 2007;22:908-912.

46. Rudolph RE, Vaughan TL, Storer BE, et al. Effect of segment length on risk for neoplastic progression in patients with Barrett esophagus. Ann Intern Med 2000;132:612-620.

47. Conio M, Cameron AJ, Romero Y, et al. Secular trends in the epidemiology and outcome of Barrett's oesophagus in Olmsted County, Minnesota. Gut 2001;48:304-309.

48. Kubo A, Cook MB, Shaheen NJ, et al. Sex-specific associations between body mass index, waist circumference and the risk of Barrett's oesophagus: a pooled analysis from the international BEACON consortium. Gut 2013;62:1684-1691.

49. Conio M, Blanchi S, Lapertosa G, et al. Long term endoscopic surveillance of patients with Barrett's esophagus. Incidence of dysplasia and adenocarcinoma: a prospective study. Am J Gastroenterol 2003;98:19311939.

50. de Jonge PJ, van Blankenstein M, Looman CW, Casparie MK, Meijer GA, Kuipers EJ. Risk of malignant progression in patients with Barrett's oesophagus: a Dutch nationwide cohort study. Gut 2010;59:1030-1036.

51. Park JJ, Kim JW, Kim HJ, et al. The prevalence of and risk factors for Barrett's esophagus in a Korean population: a nationwide multicenter prospective study. J Clin Gastroenterol. 2009;43:907-914.

52. Wong WM, Lai KC, Lam KF, et al. Prevalence, clinical spectrum and health care utilization of gastro-oesophageal reflux disease in a Chinese population: a population-based study. Aliment Pharmacol Ther 2003;18:595-604.

53. Adachi K, Mishiro T, Tanaka S, Hanada K, Kinoshita Y. Gender differences in the time-course changes of reflux esophagitis in Japanese patients. Intern Med 2015;54:869-873.

54. van Soest EM, Dieleman JP, Siersema PD, Sturkenboom MC, Kuipers EJ. Increasing incidence of Barrett's oesophagus in the general population. Gut 2005;54:1062-1066.

55. van Blankenstein M, Looman CW, Johnston BJ, Caygill CP. Age and sex distribution of the prevalence of Barrett's esophagus found in a primary referral endoscopy center. Am J Gastroenterol 2005;100:568-576.

56. Falk GW, Thota PN, Richter JE, Connor JT, Wachsberger DM. Barrett's esophagus in women: demographic features and progression to high-grade dysplasia and cancer. Clin Gastroenterol Hepatol 
2005;3:1089-1094.

57. Derakshan MH, Liptrot S, Paul J, Brown IL, Morrison D, McColl KE. Oesophageal and gastric intestinal-type adenocarcinomas show the same male predominance due to a 17 year delayed development in females. Gut 2009;58:16-23.

58. Nam SY, Choi IJ, Ryu KH, et al. The effect of abdominal visceral fat, circulating inflammatory cytokines, and leptin levels on reflux esophagitis. J Neurogastroenterol Motil 2015;21:247-254.

59. Mathieu LN, Kanarek NF, Tsai HL, Rudin CM, Brock MV. Age and sex differences in the incidence of esophageal adenocarcinoma: results from the Surveillance, Epidemiology, and End Results (SEER) Registry (1973-2008). Dis Esophagus 2014;27:757-763.

60. Grishina I, Fenton A, Sankaran-Walters S. Gender differences, aging and hormonal status in mucosal injury and repair. Aging Dis 2014;5:160-169.

61. Velders M, Schleipen B, Fritzemeier KH, Zierau O, Diel P. Selective estrogen receptor- $\beta$ activation stimulates skeletal muscle growth and regeneration. FASEB J 2012;26:1909-1920.

62. Ashcroft GS, Mills SJ, Lei K, et al. Estrogen modulates cutaneous wound healing by downregulating macrophage migration inhibitory factor. J Clin Invest 2003;111:1309-1318.

63. Honda J, Ijima K, Asanuma K, et al. Estrogen enhances esophageal barrier function by potentiating occludin expression. Dig Dis Sci 2016;61:1028-1038.

64. Orlando RC, Bryson JC, Powell DW. Mechanisms of H+ injury in rabbit esophageal epithelium. Am J Physiol 1984;246(6 Pt 1):G718G724.

65. Bhat YM, Bielefeldt K. Capsaicin receptor (TRPV1) and non-erosive reflux disease. Eur J Gastroenterol Hepatol 2006;18:263-270.

66. Chen CL. Visceral hypersensitivity in non-erosive reflux disease: neurogenic overwhelming in esophagus? Dig Dis Sci 2013;58:2131-2132.

67. Knowles $\mathrm{CH}$, Aziz Q. Visceral hypersensitivity in non-erosive reflux disease. Gut 2008;57:674-683.

68. Yiangou Y, Facer P, Dyer NH, et al. Vanilloid receptor 1 immunoreactivity in inflamed human bowel. Lancet 2001;357:1338-1339.

69. Guarino MP, Cheng L, Ma J, et al. Increased TRPV1 gene expression in esophageal mucosa of patients with non-erosive and erosive reflux disease. Neurogastroenterol Motil 2010;22:746-751, e219.

70. Yoshida N, Kuroda M, Suzuki T, et al. Role of nociceptors/neuropeptides in the pathogenesis of visceral hypersensitivity of nonerosive reflux disease. Dig Dis Sci 2013; 58: 2237-2243.

71. Greaves E, Grieve K, Horne AW, Saunders PT. Elevated peritoneal expression and estrogen regulation of nociceptive ion channels in endometriosis. J Clin Endocrinol Metab 2014;99:E1738-E1743.

72. Kim JJ, Kim N, Choi YJ, Kim JS, Jung HC. Increased TRPV1 and PAR2 mRNA expression levels are associated only with the esophageal reflux symptoms, but not with the extra esophageal reflux symptoms. Medicine (Baltimore). 2016;95:e4387.

73. Ma J, Altomare A, Guarino M, et al. HCl-induced and ATP-dependent upregulation of TRPV1 receptor expression and cytokine production by human esophageal epithelial cells. Am J Physiol Gastrointest Liver Physiol 2012;303:G635-G645.
74. Choi YJ, Kim N, Kim JJ, Lee DH, Park JH, Jung HC. Upregulation of vanilloid receptor-1 in functional dyspepsia with or without Helicobacter pylori infection. Medicine (Baltimore) 2016;95:e3410

75. Chen Y, Yang C, Wang ZJ. Proteinase-activated receptor 2 sensitizes transient receptor potential vanilloid 1 , transient receptor potential vanilloid 4, and transient receptor potential ankyrin 1 in paclitaxel-induced neuropathic pain. Neuroscience 2011;193:440-451.

76. Vega KJ, Langford-Legg T, Palacio C, Watts J, Jamal MM. Females without reflux symptoms or gastroesophageal reflux disease have less distal esophageal acid exposure than males without reflux symptoms or gastroesophageal reflux disease. Dis Esophagus 2013;26:246-249.

77. Feng G, Wang J, Zhang L, Liu Y. A study to draw a normative database of laryngopharynx $\mathrm{pH}$ profile in Chinese. J Neurogastroenterol Motil 2014;20:347-351.

78. Hartono JL, Mahadeva S, Goh KL. Anxiety and depression in various functional gastrointestinal disorders: do differences exist? J Dig Dis 2012;13:252-257.

79. Vakil N, Niklasson A, Denison H, A Rydén A. Gender differences in symptoms in partial responders to proton pump inhibitors for gastro-oesophageal reflux disease. United European Gastroenterol J 2015;3:443452.

80. Lee SP, Sung IK, Kim JH, Lee SY, Park HS, Shim CS. The effect of emotional stress and depression on the prevalence of digestive diseases. J Neurogastroenterol Motil 2015;21:273-282.

81. Fass R, Naliboff BD, Fass SS, et al. The effect of auditory stress on perception of intraesophageal acid in patients with gastroesophageal reflux disease. Gastroenterology 2008;134:696-705.

82. Dean BB, Aguilar D, Johnson LF, et al. Night-time and daytime atypical manifestations of gastro-oesophageal reflux disease: frequency, severity and impact on health-related quality of life. Aliment Pharmacol Ther 2008;27:327-337.

83. Dubois RW, Aguilar D, Fass R, et al. Consequences of frequent nocturnal gastro-oesophageal reflux disease among employed adults: symptom severity, quality of life and work productivity. Aliment Pharmacol Ther 2007;25:487-500.

84. Kim JY, Kim N, Seo PJ, et al. Association of sleep dysfunction and emotional status with gastroesophageal reflux disease in Korea. J Neurogastroenterol Motil 2013;19:344-354.

85. Kannampalli P, Sengupta JN. Role of principal ionotropic and metabotropic receptors in visceral pain. J Neurogastroenterol Motil 2015;21:147-158.

86. Nan J, Liu J, Mu J, et al. Brain-based correlations between psychological factors and functional dyspepsia. J Neurogastroenterol Motil 2015;21:103-110.

87. Zhang J, Banerjee B. Role of microRNA in visceral pain. J Neurogastroenterol Motil 2015;21:159-171.

88. Hershcovici T, Fass R Nonerosive reflux disease (NERD) - an update. J Neurogastroenterol Motil 2010;16:8-21.

89. Seedat S, Scott KM, Angermeyer MC, et al. Cross-national associations between gender and mental disorders in the World Health Organization World Mental Health Surveys. Arch Gen Psychiatry 2009;66:785-795.

90. Lovell RM, Ford AC. Effect of gender on prevalence of irritable bowel 
syndrome in the community: systematic review and meta-analysis. Am J Gastroenterol 2012;107:991-1000.

91. Castell DO. Esophageal disorders in the elderly. Gastroenterol Clin North Am 1990;19:235-254.

92. Castell DO. How is esophageal sensitivity impaired with age? In: Giuli R, ed. The esophageal mucosa. Amsterdam: Elsevier Science BV 1994;267-269.

93. Min YW, Lim SW, Lee JH, et al. Prevalence of extraesophageal symptoms in patients with gastroesophageal reflux disease: a multicenter questionnaire-based study in Korea. J Neurogastroenterol Motil 2014;20:87-93.

94. You CR, Oh JH, Seo M, et al. Association between non-erosive reflux disease and high risk of obstructive sleep apnea in Korean population. J Neurogastroenterol Motil 2014:30;20:197-204.

95. Lee HJ, Kim HM, Kim N, et al. Association between halitosis diagnosed by a questionnaire and halimeter and symptoms of gastroesophageal reflux disease. J Neurogastroenterol Motil 2014;20:483-490.

96. Nasseri-Moghaddam S, Mofid A, Ghotbi MH, et al. Epidemiological study of gastro-oesophageal reflux disease: reflux in spouse as a risk factor. Aliment Pharmacol Ther 2008;28:144-153.

97. do Rosário Dias de Oliveira Latorre M, Medeiros da Silva A, Chinzon D, Eisig JN, Dias-Bastos TR. Epidemiology of upper gastrointestinal symptoms in Brazil (EpiGastro): a population-based study according to sex and age group. World J Gastroenterol 2014;20:17388-17398.

98. Nguyen P, Lee SD, Castell DO. Evidence of gender differences in esophageal pain threshold. Am J Gastroenterol 1995;90:901-905.

99. Kapur N, Hunt I, Lunt M, McBeth J, Creed F, Macfarlane G. Primary care consultation predictors in men and women: a cohort study. $\mathrm{Br}$ J Gen Pract 2005;55:108-113.

100. Bruley Des Varannes S, Marek L, Humeau B, Lecasble M, Colin R. Gastroesophageal reflux disease in primary care. Prevalence, epidemiology and quality of life of patients. Gastroenterol Clin Biol 2006;30:364-370.

101. Locke GR III, Talley NJ, Fett SL, Zinsmeister AR, Melton LJ III. [Prevalence and clinical spectrum of gastroesophageal reflux: a population-based study in Olmsted County, Minnesota.] Gastroenterology 1997;112:1448-1456. [French]

102. Kennedy T, Jones R. The prevalence of gastro-oesophageal reflux symptoms in a UK population and the consultation behaviour of patients with these symptoms. Aliment Pharmacol Ther 2000;14:1589-1594.

103. Ho KY, Kang JY, Seow A. Patterns of consultation and treatment for heartburn: findings from a Singaporean community survey. Aliment Pharmacol Ther 1999;13:1029-1033.

104. Katz PO, Gerson LB, Vela MF. Guidelines for the diagnosis and management of gastroesophageal reflux disease. Am J Gastroenterol 2013;108:308-328.

105. Park CH, Kim HS, Lee SK, et al. Effects of the new prokinetic agent DA-9701 formulated with Corydalis Tuber and Pharbitis Seed in patients with minimal change esophagitis: a bicenter, randomized, double blind, placebo-controlled study. J Neurogastroenterol Motil 2014;20:338-346.

106. Dickman R, Maradey-Romero C, Gingold-Belfer R, Fass R. Unmet needs in the treatment of gastroesophageal reflux disease. J Neurogastroenterol Motil 2015;21:309-319.
107. Kim SE, Kim N, Oh S, et al. Predictive factors of response to proton pump inhibitors in Korean patients with gastroesophageal reflux disease. J Neurogastroenterol Motil 2015;21:69-77.

108. Maradey-Romero C, Fass R. New and future drug development for gastroesophageal reflux disease. J Neurogastroenterol Motil 2014;20:616.

109. Niu XP, Yu BP, Wang YD, et al. Risk factors for proton pump inhibitor refractoriness in Chinese patients with non-erosive reflux disease. World J Gastroenterol 2013;19:3124-3129.

110. El-Serag H, Becher A, Jones R. Systematic review: persistent reflux symptoms on proton pump inhibitor therapy in primary care and community studies. Aliment Pharmacol Ther 2010;32:720-737.

111. Ruigomez A, Johansson S, Wernersson B, et al. Gastroesophageal reflux disease in primary care: using changes in proton pump inhibitor therapy as an indicator of partial response. Scand J Gastroenterol 2012;47:751761.

112. Heading RC, Monnikes H, Tholen A, et al. Prediction of response to PPI therapy and factors influencing treatment outcome in patients with GORD: a prospective pragmatic trial using pantoprazole. BMC Gastroenterol 2011;11:52.

113. Bytzer P, van Zanten SV, Mattsson H, Wernersson B. Partial symptomresponse to proton pump inhibitors in patients with non-erosive reflux disease or reflux oesophagitis - a post hoc analysis of 5796 patients. Aliment Pharmacol Ther 2012;36:635-643.

114. Labenz J, Armstrong D, Zetterstrand S, Eklund S, Leodolter A. Clinical trial: factors associated with resolution of heartburn in patients with reflux oesophagitis-results from the EXPO study. Aliment Pharmacol Ther 2009;29:959-966.

115. Lundell L, Hatlebakk J, Galmiche JP, et al. Long-term effect on symptoms and quality of life of maintenance therapy with esomeprazole 20 mg daily: a post hoc analysis of the LOTUS trial. Curr Med Res Opin 2015;31:65-73.

116. Becker V, Grotz S, Schlag C, et al. Positive predictors for gastroesophageal reflux disease and the therapeutic response to proton-pump inhibitors. World J Gastroenterol 2014;20:4017-4024.

117. Wang AJ, Wang H, Xu L, et al. Predictors of clinical response of acid suppression in Chinese patients with gastroesophageal reflux disease. Dig Liver Dis 2013;45:296-300.

118. Ashcroft GS, Greenwell-Wild T, Horan MA, Wahl SM, Ferguson MW. Topical estrogen accelerates cutaneous would healing in aged humans associated with an altered inflammatory response. Am J Pathol 1999;155:1137-1146.

119. Ashcroft GS, Dodsworth J, van Boxtel E, et al. Estrogen accelerates cutaneous wound healing associated with an increase in TGF-beta1 levels. Nat Med 1997;3:1209-1215.

120. Menon S, Nightingale P, Trudgill N. Is hormone replacement therapy in post-menopausal women associated with a reduced risk of oesophageal cancer? United European Gastroenterol J 2014;2:374-382.

121. Green J, Czanner G, Reeves G, et al. Menopausal hormone therapy and risk of gastrointestinal cancer: nested case-control study within a prospective cohort, and meta-analysis. Int J Cancer 2012;130:2387-2396.

122. Lagergren J, Nyrén O. Do sex hormones play a role in the etiology of 
esophageal adenocarcinoma? A new hypothesis tested in a populationbased cohort of prostate cancer patients. Cancer Epidemiol Biomarkers Prev 1998;7:913-915.

123. Nordenstedt H, Zheng Z, Cameron AJ, Ye W, Pedersen NL, Lagergren J. Postmenopausal hormone therapy as a risk factor for gastroesophageal reflux symptoms among female twins. Gastroenterology 2008;134:921-928.
124. Hirsch DP, Holloway RH, Tytgat GN, Boeckxstaens GE. Involvement of nitric oxide in human transient lower esophageal sphincter relaxations and esophageal primary peristalsis. Gastroenterology 1998;115:13741380.

125. Nilsson M, Johnsen R, Ye W, Hveem K, Lagergren J. Obesity and estrogen as risk factors for gastroesophageal reflux symptoms. JAMA 2003;290:66-72. 